\title{
SIMULTANEOUS OPTIMIZATION OF SUPERVISORY CONTROL AND GEAR SHIFT LOGIC FOR A PARALLEL HYDRAULIC HYBRID REFUSE TRUCK USING STOCHASTIC DYNAMIC PROGRAMMING
}

\author{
Rajit Johri \\ Mechanical Engineering, \\ University of Michigan \\ Ann Arbor, Michigan, USA \\ 48109 \\ rajit@umich.edu
}

\author{
Simon Baseley \\ Bosch Rexroth Corporation \\ 2730 Research Drive \\ Rochester Hills, MI, USA, 48309 \\ Simon.Baseley@boschrexroth- \\ us.com
}

\author{
Zoran Filipi ${ }^{*}$ \\ Mechanical Engineering, \\ University of Michigan \\ Ann Arbor, Michigan, USA \\ 48109 \\ filipi@umich.edu \\ * Corresponding Author
}

\begin{abstract}
The power management controller of a hybrid vehicle orchestrates the operation of onboard energy sources, namely engine and auxiliary power source with the goal of maximizing performance objectives such as the fuel economy. The paper focuses on optimization of the power management strategy of the refuse truck with parallel hydraulic hybrid powertrain. The high power density of hydraulic components and high charging/discharging efficiency of accumulator with no power constraint make hydraulic hybrid an excellent choice for heavyduty stop and go application. Two power management strategies for a parallel hydraulic hybrid refuse truck are compared; heuristic and stochastic dynamic programming based optimal controller. For designing a SDP based controller, an infinite horizon problem is setup with power demand from driver modeled as random Markov process. The objective is to maximize system level efficiency by optimizing (i) the power split between engine and hydraulic propulsion unit, and (ii) gear shift schedule. This combines the optimization of powertrain parameters with power management design.
\end{abstract}

Keywords: stochastic dynamic programming (SDP), parallel hydraulic hybrid, supervisory control, optimal control

\section{INTRODUCTION}

Development of alternative powertrains is driven by the need to address the energy security and climate change with increased fuel economy. Hybridization provides a significant leap in fuel economy improvements. Hybridization of trucks has very profound impact on global petroleum consumption. Trucks spend a lot more time on road and their annual fuel consumption per vehicle is very large In US, the total fuel consumption of trucks has already surpassed the consumption of passenger cars. However, the chances for improving fuel economy of trucks are limited. They already employ very efficient diesel engines. Lightweight structures for truck body design will likely improve freight efficiency rather than fuel economy, as the payload and load per axle dictates overall weight. There is also a limit in reducing aerodynamic drag for trucks. In contrast, hybridization offers significant potential for fuel economy improvement through efficient management of the secondary source of energy and utilization of additional degrees of freedom in the system.

Hybrid vehicles use secondary storage of energy like battery, accumulator and a secondary source of power like electric motor/generator or hydraulic pump/motor. The whole powertrain can be designed to improve fuel economy by (i) downsizing the engine, (ii) recovering energy during braking, (iii) optimizing engine operation and, (iv) engine shutdowns. However, the vehicle system becomes more complex and requires sophisticated control strategy to maximize the benefits.

The refuse truck used in this study is retrofitted with parallel hydraulic system. Previous work done by Filipi et al. [1], [2], [3] in this field have shown hydraulics to be well suited for truck application due to their high power density and high energy conversion efficiency. A side benefit of hydraulic hybrids is lower foundation brake maintenance cost as hydraulic motors can be used aggressively during braking thereby minimizing wear on brakes. The objective of this paper is to find optimal control policy for engine and motor operation, combined with simultaneous development of optimal gear shifting strategy. The parallel hybrid vehicle has a secondary power source post transmission and the interaction of engine and pump is affected by gear shifting. Therefore, the gear shift 
logic is optimized along with supervisory controller to maximize real-world benefits.

The paper is organized in four sections. First the modeling of conventional refuse truck is explained, including descriptions of physics-based models. This establishes a baseline for evaluating fuel economy improvements with hybridization. Next, the parallel hydraulic hybrid configuration is proposed and the additional component modeling for hydraulic hybrid is introduced. The subsequent section describes the two power management strategies; rule based and stochastic dynamic programming based optimal controller. The results from these two strategies are compared and insights on reasons for different performance are offered. The paper ends with conclusions.

\section{MODELING OF REFUSE TRUCK}

\section{Conventional Model}

The baseline vehicle modeled and studied in this paper is a 4X2 refuse truck. Table 1 gives the baseline vehicle specifications. The vehicle is modeled in SIMULINK and is based on vehicle simulation platform developed at the University of Michigan [4]. The powertrain system simulation was validated for a class VI truck and has been appropriately scaled for this study.

TABLE 1 : REFUSE TRUCK SPECIFICATIONS

\begin{tabular}{lll}
\hline Engine & Description & Cummins ISC 07- 285 \\
& Max. Power & 208 kW @ 2600 RPM \\
& Max. Torque & $800 \mathrm{lb}-\mathrm{ft} @ 1300 \mathrm{RPM}$ \\
\hline Transmission & Design & Allison 5 speed \\
& Gear Ratio & $3.51,1.9,1.44,1,0.74$ \\
\hline Vehicle & Type & $4 \times 2$ Refuse Truck \\
& Weight & $18080 \mathrm{~kg}$ \\
& Coeff. of Drag & 0.8 \\
& Frontal Area & $8.94 \mathrm{~m}^{2}$ \\
& Tire Radius & $0.505 \mathrm{~m}$ \\
& Final Drive Ratio & 6.14 \\
\hline
\end{tabular}

The engine model is based on look-up table which outputs engine torque as a function of fuel input and engine speed. The engine speed is then calculated by

$$
\omega_{e}=\frac{1}{I_{e}} \int\left(T_{e}-T_{i}\right) d t
$$

where $I_{e}$ is engine inertia, $\omega_{e}$ and $T_{e}$ are engine speed and torque respectively and $T_{i}$ is the impeller torque from torque converter. A diesel engine fuel injector controller provides the mass of fuel injected to the lookup table based on throttle command and engine speed. A turbo-lag is simulated by including a delay in injection with time constant calibrated based on data obtained from engine testing [2].

The Refuse truck is equipped with 5-speed Allison automatic transmission. The torque converter is modeled using capacity factor and torque ratio curves.

$$
T_{i}=\left(\frac{f_{K}(S R)}{\omega_{e}}\right)^{2}
$$

where, $f_{k}$ is the capacity factor function and SR is the speed ratio between engine speed and turbine (transmission output) speed, i.e. $S R=\omega_{\text {turbine }} / \omega_{e}$. The torque converter includes a lockup clutch that is controlled by a lock logic based on vehicle speed and driver demand. The transmission fluid churning losses are modeled as a variable nonlinear resistance that varies with the gear number.

The gearbox is modeled as a finite state machine with different gear being the different states of the system. A blending function is added to simulate inertia and torque phase during gear shift. Blending function provides a fast and fairly accurate way of incorporating these phases. The gear shifting logic is based on transmission output speed and engine throttle shown in Figure 1.

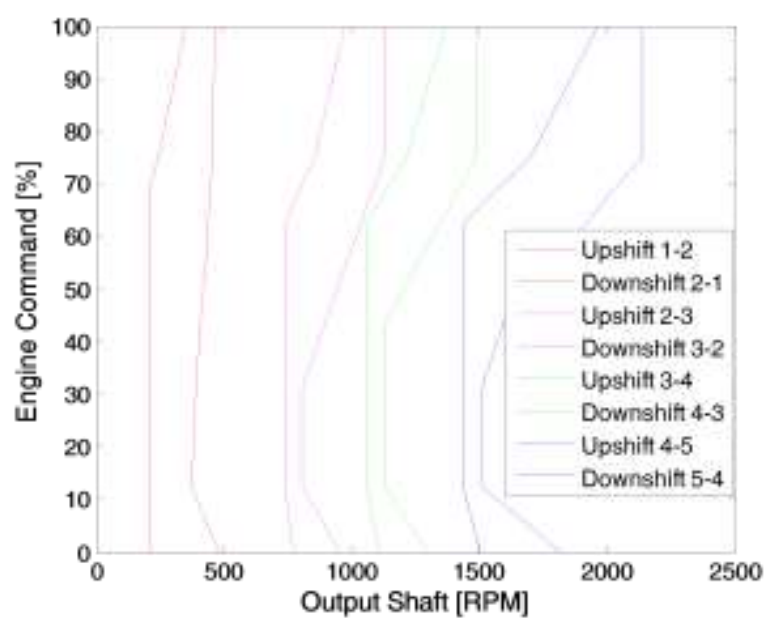

FIGURE 1: SHIFT MAP

The vehicle is modeled as point mass system and pitch plane dynamics are ignored. This is deemed sufficient for the fuel economy studies. The resistive forces modeled are rolling and drag resistance. The vehicle also contains a brake model, which acts as a coulombic friction device.

\section{Parallel Hydraulic Hybrid Powertrain Model}

The parallel hydraulic hybrid refuse truck is modeled similarly to the conventional truck with the hydraulic components and the integration approach described by $\mathrm{Wu}$ et al. [1], [2]. Table 2 gives the specifications of the hybrid refuse 
truck. A parallel configuration with a post transmission motor is selected for this study. Figure 2 shows the schematic of the proposed hybrid powertrain. The powertrain configuration and component sizing are suggested by the manufacturer of hydraulic components. Considerations are based on engineering studies, cost effectiveness, availability of components and packaging constraints.

TABLE 2: PARALLEL HYDRAULIC HYBRID SPECIFICATIONS

\begin{tabular}{lll}
\hline Engine & Description & Cummins ISC 07- 285 \\
& Max. Power & 208 kW @ 2600 RPM \\
& Max. Torque & 800 lb-ft @ 1300 RPM \\
\hline Pump & Design & Axial Piston Variable \\
& & Displacement \\
& Size & $210 \mathrm{cc} / \mathrm{rev}$ \\
& Speed Limit & $2300 \mathrm{RPM}$ \\
& Max Power & $253 \mathrm{~kW} @ 315 \mathrm{bar} @$ \\
& & $2300 \mathrm{RPM}$ \\
\hline Accumulator & Capacity (Max. & $32 \mathrm{Liter}$ \\
& Gas Volume) & \\
& Max Pressure & $315 \mathrm{bar}$ \\
& Min Pressure & $125 \mathrm{bar}$ \\
\hline Vehicle & Type & $4 \mathrm{X} 2 \mathrm{Refuse}$ Truck \\
& Weight & $18530 \mathrm{~kg}$ \\
& Coeff. of Drag & 0.8 \\
& Frontal Area & $8.94 \mathrm{~m}{ }^{2}$ \\
& Tire Radius & $0.505 \mathrm{~m}$ \\
& Final Drive Ratio & 6.14 \\
\hline Transmission & Design & Allison 5 speed \\
& Gear Ratio & $3.51,1.9,1.44,1,0.74$ \\
\hline
\end{tabular}

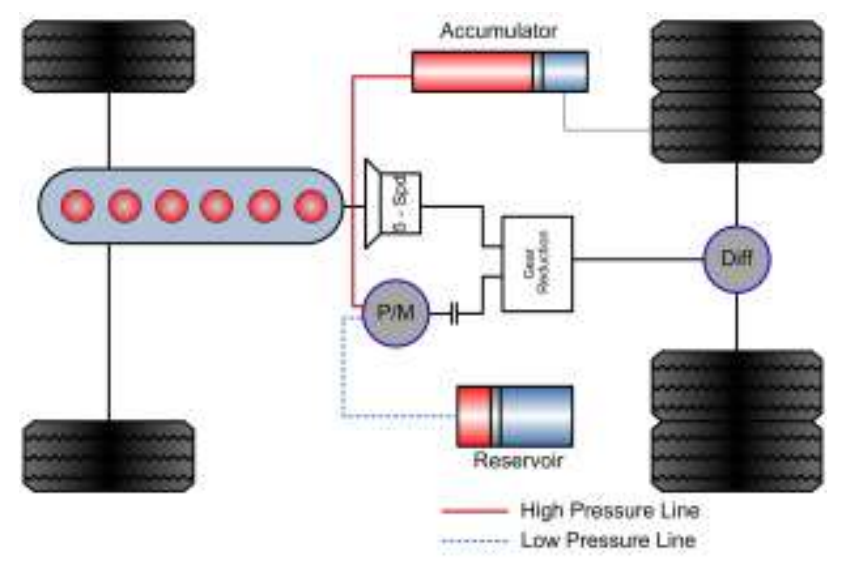

FIGURE 2: PARALLEL HYDRAULIC HYBRID ARCHITECTURE

The hydraulic hybrid is particularly well suited for heavy trucks due to large rates of energy flow through the drivetrain. The hydraulic accumulator is capable of accepting high rate of charging or discharging, unlike electric batteries. Refuse truck duty cycle comprises of frequent acceleration and deceleration, and hydraulic hybrid is particularly well suited for such application. The vehicle has two propulsion sources. The same engine otherwise used for the conventional drivetrain is retained for the HHV. The engine hasn't been downsized in this study because of the gradeability constraint. The secondary power source is a hydraulic bent-axis pump/motor with variable displacement. The motor is reversible and can be operated as a pump to recuperate energy during braking.

The pump/motor is an axial piston type design and is modeled based on modified Wilson's theory [5]. The pump/motor displacement command varies the stroke and controls the torque and flow. The theoretical flow and torque are calculated which are then corrected by the volumetric and torque losses respectively. The volumetric losses encompass the laminar, compressibility and turbulent leakage, and the torque losses comprise viscous, hydrodynamic and mechanical. The expressions include constants than need to be calibrated using available experimental data [6], but once that is accomplished the model is capable of capturing effects of all operating parameters. The detailed implementation of pump/motor is given by Filipi et al. [2] and Kim et al. [3].

The hydraulic accumulator is the secondary energy storage device for hydraulic hybrids. It is a hydro-pneumatic device and stores energy by compressing the nitrogen gas. A positive fluid flow rate into the accumulator compresses the gas stored in the bladder, thus storing energy. A low pressure reservoir is used in the system to prevent cavitation of hydraulic devices. In order to correctly predict the accumulator dynamic performance and efficiency, a full thermodynamic model is used. Ideal gas laws cannot be used to describe the dynamics of gas due to high pressures in the accumulator, and hence Benedict-Webb-Rubin equation is used to predict real gas properties [2], [5]. Also the heat transfer effects cannot be ignored as accumulator undergoes frequent charging and discharging resulting in huge temperature changes. The accumulator is modeled with elastomeric foam on the gas side to increase the thermal time constant [7] and achieve high conversion efficiencies in midnineties. The SOC is defined as the ratio of instantaneous fluid volume $V$ to accumulator fluid capacity:

$$
S O C=\frac{V-V_{\min }}{V_{\max }-V_{\min }}
$$

\section{POWER MANAGEMENT}

Hybrid vehicles have additional energy source onboard. This brings added flexibility which allows for better fuel economy and reduced emissions but added degree of freedom brings challenges and complexity in designing and control of vehicle. Supervisory controller plays an important role in orchestrating multiple power sources to achieve desired objectives. A large body of work exists in this field with different control and optimization techniques ranging from rule-based [1], to Equivalent Consumption Minimization Strategy [8], fuzzy logic [9], [10] and horizon optimization using dynamic programming [4], [11], [12].

This paper will analyze two control strategies. The first one is a traditional rule based algorithm and is derived from the work done by $\mathrm{Wu}$ et al. [1]. Hydraulic energy is used for 
launching the vehicle to avoid inefficient engine operation and effective regeneration. The controller uses motor until the SOC is completely depleted. If the power available from hydraulics is not enough, engine supplements the motor power. The idea is to empty the accumulator in anticipation of next braking event and hence regenerate maximum amount of energy. The stock gear shift logic is used without any modifications in this case.

The proposed advanced algorithm is based on Stochastic Dynamic Programming (SDP). The algorithm simultaneously optimizes the power split between engine and hydraulic pump, and gear shift logic. The optimal benchmark obtained by the Dynamic programming (DP) process is not implementable because of the forward looking nature and subsequent rule extraction sacrifices some of the fuel economy potential [2]. The SDP eliminates the rule extractions step and allows direct development of an implementable control strategy for vehicle supervisory control. SDP is not based on a particular driving cycle (time signal), but rather the statistical characteristics of many driving cycles and hence it is non-cycle-beating. It has been previously applied to a parallel hybrid electric vehicle by Lin et al. [13] and Liu et al. [14] and, to a series hydraulic hybrid by Johri et al. [15]. The rule based algorithm serves as baseline for assessing the effectiveness of the new approach which applies SDP to simultaneously address powersplit decision and gear shift in the transmissions.

\section{Rule Based Controller}

The rule based supervisory controller is derived from the work previously done by $\mathrm{Wu}$ et al. [1] at University of Michigan. The vehicle used for their study was an International 4700 Series Class VI 4X2 truck. DP was applied to develop control strategies for optimally controlling the two power sources and achieve the best possible fuel economy. The DP searched for optimal decisions at discrete points in time sequence. Since, DP algorithm is forward looking; the results cannot be directly implemented without the knowledge of future driving conditions. Wu et al. analyzed the results from DP to extract the power management rules which are practically implementable.

The key findings of DP algorithm applied to parallel hydraulic hybrid [1] are: (i) Hydraulic energy is favored for launch, (ii) DP tends to use motor and engine exclusively, i.e. DP tries to use motor if SOC is higher than threshold, but switches to engine power frequently when power demand exceeds maximum motor power, and (iii) DP ensures the accumulator is empty before braking event for maximum regeneration.

The control rules implemented in this paper are derived from these guidelines with consideration to practicality. Motor is used to launch the vehicle and is used until minimum SOC is reached. This prevents engine and motor aggressively trading roles as the primary source of propulsion power as suggested by DP. Also, keeping SOC at minimum prepares for next braking event. The pseudo-code in Table 3 gives the power management rules with $P$ denotes the power.

\section{TABLE 3: POWER MANAGEMENT RULES [1]}

$$
\begin{aligned}
& \text { Driving } \\
& \text { if } S O C>0 \\
& P_{\text {moior }}=\min \left(P_{\text {demand }}, P_{\text {mowor_max }}\right) \\
& P_{\text {engine }}=P_{\text {demand }}-P_{\text {motor }} \\
& \text { else } \\
& P_{\text {engine }}=P_{\text {demand }} \\
& P_{\text {moior }}=0 \\
& \text { end }
\end{aligned}
$$

$$
\begin{aligned}
& \text { Braking } \\
& \text { if } S O C<1 \\
& \quad P_{\text {pump }}=-\min \left(\left|P_{\text {demand }}\right|, P_{\text {pump_max }}\right) \\
& \quad P_{\text {fric_trake }}=P_{\text {demand }}-P_{\text {pump }} \\
& \text { else } \\
& \quad P_{\text {friction_brake }}=P_{\text {demand }} \\
& \quad P_{\text {pump }}=0 \\
& \text { end }
\end{aligned}
$$

\section{Behavior of the system with rule based strategy}

Figure 3 shows the Rule based controller hydraulic hybrid refuse truck simulation results for a test cycle. Hydraulic motor provides the power for vehicle launch. As the hydraulic energy depletes, the motor power is supplemented by engine until SOC drops to minimum. Then the engine provides the propulsion power as a sole source. During braking, the motor is used for regeneration.

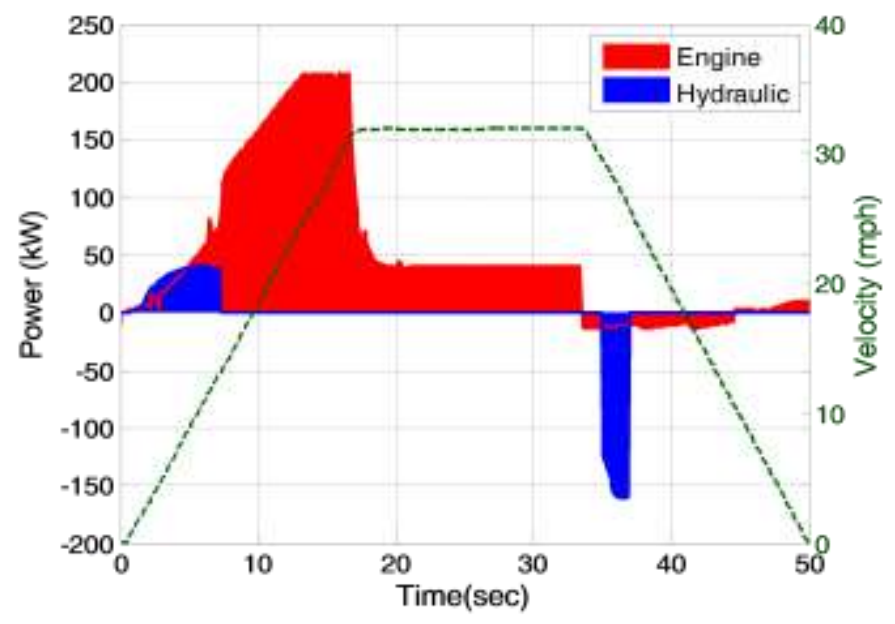

FIGURE 3: RULE BASED CONTROL STRATEGY 
Figure 4 shows the engine visitation points over BSFC map by simulating parallel hydraulic hybrid over federal urban driving schedule (FUDS). It can be seen from the Figure 4 that engine never operates at low speed regions.

The parallel hydraulic hybrid refuse truck with rule based controller is also simulated over actual driving cycles recorded over typical city routes (Figure 5). The frequent starts and stops provide opportunity for hydraulic assist launch and regenerative braking. However, the small periods of highway driving introduce a challenge, as the engine operation is pushed to high speed/high load regions and reduce opportunities for improvements. The Table 4 shows the fuel economy improvement with hydraulic hybrid over conventional refuse truck. Hybridization results in around 13\% improvement for most real world driving cycles.

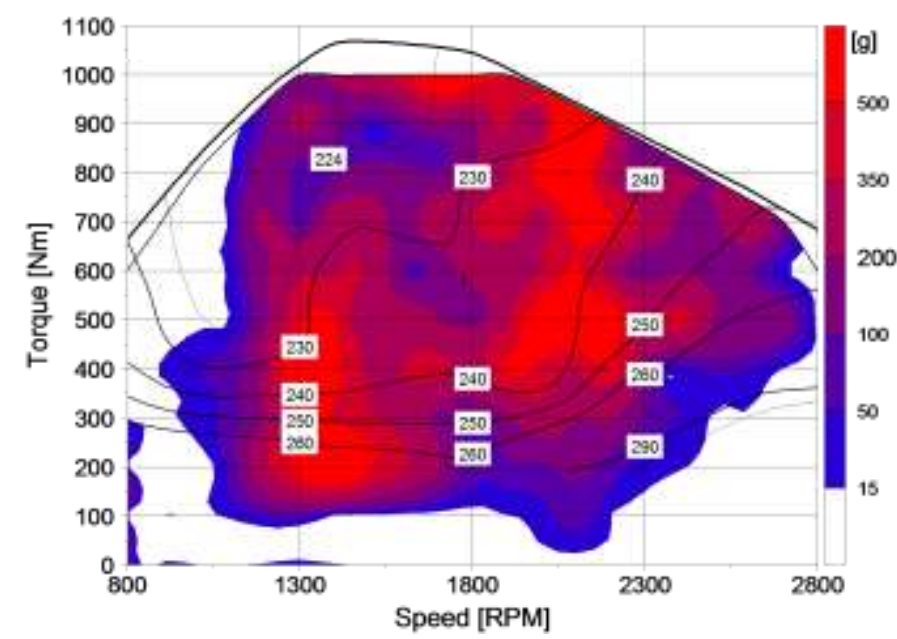

FIGURE 4: ENGINE VISITATION POINTS ON THE BSFC MAP, WITH A COLOR SCALE INDICATING THE RELATIVE AMOUNT OF FUEL CONSUMED IN A GIVEN ZONE DURING FUDS FOR RULE BASED CONTROLLER

\section{Stochastic Dynamic Programming}

The problem of determining optimal power split policy between two sources (engine and hydraulic motor) can be formulated as an infinite horizon, discounted Markov decision problem defined over state space, $S \in R^{n}$. The objective of the problem is to solve for control policy $u=\pi(x), x \in S$, that minimizes the expected total cost, $J_{\pi}$ over an infinite horizon

$$
J_{\pi}\left(x_{0}\right)=\lim _{N \rightarrow \infty} E\left\{\sum_{k}\left\{\sum_{k=0}^{N-1} \gamma^{\kappa} g\left(x_{k}, \pi\left(x_{k}\right), w_{k}\right)\right\}\right.
$$

where $g$ is the instantaneous cost function and depends on the state vector, $x$, disturbance, $w$, and stationary control policy, $\pi$ at any given instant $k . J_{\pi}\left(x_{0}\right)$ is the expected cost given initial condition, $x_{0}$ and follows the stationary policy $\pi .0<\gamma<1$ is the discount factor and signifies that the tradeoff between future cost with present cost. The instantaneous cost $g$ is defined as the fuel consumption by the engine.
In discrete time, the hydraulic hybrid vehicle model can be expressed as

$$
x(k+1)=f(x(k), u(k), w(k))
$$

where $x(k)$ is the vector of state variables, $u(k)$ is the vector of control variables and $w(k)$ is the vector of disturbance to the system. The state vector, $x$ (consists of accumulator SOC and vehicle speed $\left.\omega_{w h}\right)$ for hydraulic hybrid vehicle evolves deterministically. The evolution of state vector is constrained by dynamics of vehicle, engine and hydraulics.

$$
\begin{aligned}
& P_{d e m, k}=P_{e, k}+P_{m, k} \\
& \omega_{e, k}=\omega_{w h, r e q} \cdot F D \cdot G R \\
& \omega_{e, \min } \leq \omega_{e, k} \leq \omega_{e, \max } \\
& T_{e, \min }\left(\omega_{e, k}\right) \leq T_{e, k}\left(\omega_{e, k}\right) \leq T_{e, \max }\left(\omega_{e, k}\right) \\
& T_{m, \min }\left(\omega_{m, k}, S O C_{k}\right) \leq T_{m, k} \leq T_{m, \max }\left(\omega_{m, k}, S O C_{k}\right) \\
& S O C_{\min } \leq S O C_{k} \leq S O C_{\max }
\end{aligned}
$$

where $P, T, \omega$ denotes power, torque and speed respectively, with subscripts $e, m, w_{h}$ referring to engine, motor and wheel respectively. $F D$ is the final drive ratio and GR is the gear ratio of the selected gear.

The power demand from the driver is stochastic in nature and can be treated as disturbance to the system. Driver demand can be modeled as a discrete-time stochastic dynamic process, and a stationary Markov chain can be used to generate the next power demand from driver, $P_{d e m}$. The dynamics of driver power demand is assumed to be

$$
P_{d e m, k+1}=w_{k}
$$

where the probability distribution of $\mathrm{w}_{\mathrm{k}}$ is assumed to be

$$
\begin{aligned}
& p_{i j, l}=\operatorname{Pr}\left\{w=P_{d e m}^{j} \mid P_{d e m}=P_{d e m}^{i}, \omega_{w h}=\omega_{w h}^{l}\right\} \\
& i, j=1,2, \ldots, N_{p} \quad l=1,2, \ldots, N_{\omega}
\end{aligned}
$$

where $p_{i l, j}$ represent the one-step transition probability, $\omega_{w h}$ is the wheel speed. $N_{p}$ and $N_{w}$ is the cardinality of discretized power demand vector and wheel speed vector, respectively.

To generate the driver demand transition probability matrices, the real world refuse truck driving cycles, Figure 5 are recorded and statistically sampled. Using model and the sampled driving cycles, sequence of observation $\left(P_{d e m}, \omega_{w h}\right)$ are calculated and then mapped to sequence of quantized states. The transition probability then can be calculated using maximum likelihood estimator.

The control vector, $u(k)$ is the optimal engine power demand, $P_{e}$ and the optimal gear shift at that instant $k$ given state vector $x(k)$. This is different from the previous work done 
by Lin et al. [13] and other authors on parallel hybrid electric vehicle. Previous researchers used only the desired engine power as the control input and assumed the baseline shift schedule. This work combines the optimization of gear shift schedule with power split policy. The expectation is that the combined optimization approach will give better results than sequentially optimizing for gear shift schedule first and then power management.
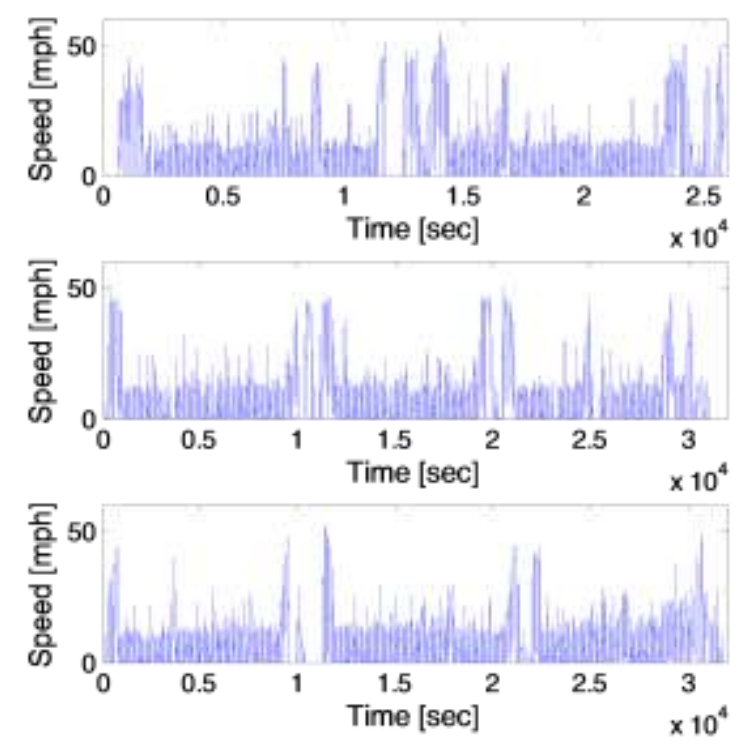

\section{FIGURE 5: REAL-WORLD REFUSE TRUCK DRIVING CYCLES}

The optimal cost-to-go vector is solved using Hybrid Policy/Value Iteration Algorithm. The algorithm starts with an initial policy $\pi_{0}$ and generates sequence of updated policies $\pi_{1}$, $\pi_{2} \ldots$ with every iteration. The policy iteration algorithm iterates between a policy evaluation step and a policy improvement step until the optimal cost function converges. In policy evaluation step, given a policy $\pi_{k}, J \pi_{k}(x)$ is calculated by solving linear set of equations

$$
J_{\pi}^{k+1}\left(x^{i}\right)=g\left(x^{i}, \pi\left(x^{i}\right), w^{i}\right)+\underset{w}{E}\left\{\gamma J_{\pi}^{k}\left(x^{\prime}\right)\right\}
$$

for all $i$, where $k$ is the iteration number, and $x^{\prime}$ is the new state, i.e., $x^{\prime}=f\left(x_{i}, \pi\left(x_{i}\right), w\right)$. The policy improvement step is evaluated next and updated policy $\pi_{k+1}$ is calculated.

$$
\pi^{\prime}\left(x^{i}\right)=\underset{u \in U\left(x^{i}\right)}{\arg \min }\left[g\left(x^{i}, u, w^{i}\right)+\underset{w}{E}\left\{\gamma J_{\pi}\left(x^{i}\right)\right\}\right]
$$

for all $i$, where $J_{\pi}$ is the approximate cost function obtained from the policy evaluation step.

The Figure 6 and Figure 7 shows the control maps for engine power demand and gear selection for a particular vehicle speed based on instantaneous driver power demand and SOC.
The SDP algorithm is capable of producing such a set of maps for any vehicle speed. Therefore, the practical controller comprises of set of maps, in this case 16, and an interpolation routine. This results in reasonable memory requirements and full state feedback lookup produces a robust controller.

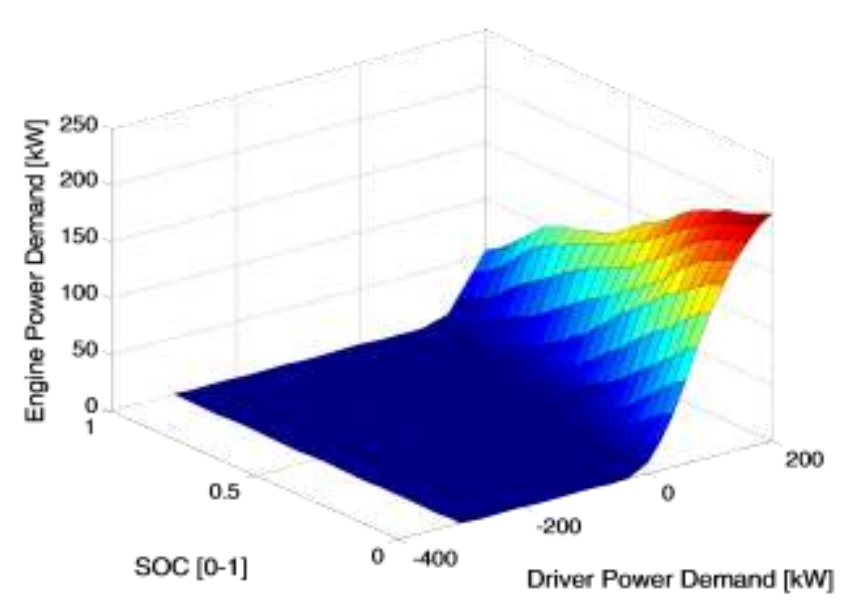

FIGURE 6: OPTIMAL ENGINE POWER DEMAND 3-D STATE FEEDBACK LOOKUP FOR A PARTICULAR WHEEL SPEED

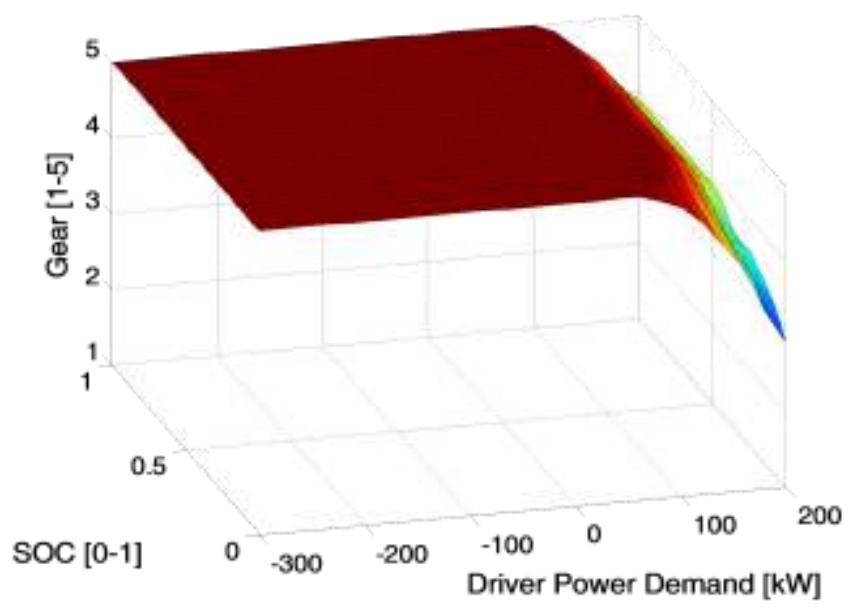

FIGURE 7: OPTIMAL GEAR SHIFT SCHEDULE FOR A PARTICULAR WHEEL SPEED

\section{Results with the advanced SDP controller}

Figure 8 shows the engine visitation points for SDP based controller. It can be seen that the engine operates in higher loads and lower BSFC regions more frequently with SDP compared to Rule based controller - see Figure 4 for comparison. This is due to two reasons.

Firstly, the SDP based controller uses optimal shift schedule which anticipates driver actions. Figure 9 shows the gear selection for rule based and SDP based controller over a section of FUDS. It can be seen that SDP based controller generally upshifts to higher gears and thereby operates engine 
at lower speeds higher loads. At other instances in which the SDP based controller anticipates acceleration are the exceptions. In these cases SDP chooses to downshift and prepare for a severe transient.

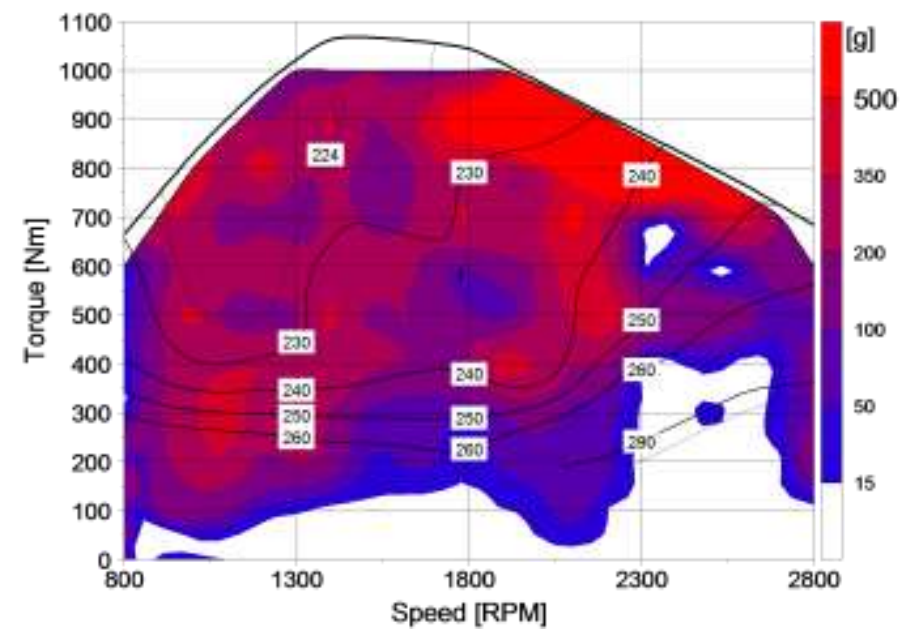

FIGURE 8: ENGINE VISITATION POINTS ON THE BSFC MAP, WITH A COLOR SCALE INDICATING THE RELATIVE AMOUNT OF FUEL CONSUMED IN A GIVEN ZONE DURING FUDS DRIVING SCHEDULE FOR SDP BASED CONTROLLER

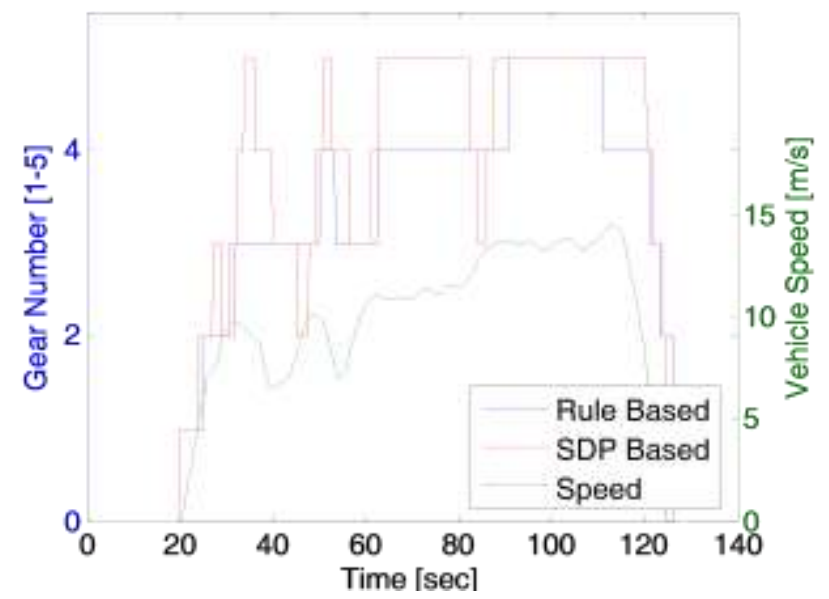

FIGURE 9: GEAR SHIFT SCHEDULE - SDP VS RULE BASED

Secondly, the SDP based controller deviates significantly from the rule based controller in power split strategy. The launch in SDP based controller is purely hydraulic, like in rule based controller. During driving, rule based controller tries to meet power demand with hydraulic motor and supplements it with engine power if motor power falls short. The strategy is always hydraulic first. However, SDP based controller tries to maximize the combined efficiency of engine and motor operation. The ratio of power from engine and motor varies with vehicle velocity and SOC of accumulator with the sole objective of maximizing the fuel economy. This is further illustrated in Figure 10. The SDP controller never fully depletes the hydraulic accumulator to minimum SOC and blends the engine and hydraulic power when SOC drops low. The hydraulic pump is used to provide high frequency transient power demand from driver and helps engine operate more smoothly. Also the SDP controller is able to capture more energy during braking because the SDP controller keeps SOC slightly higher than rule based controller and amount of braking torque that can be applied at any instant is proportional to SOC.
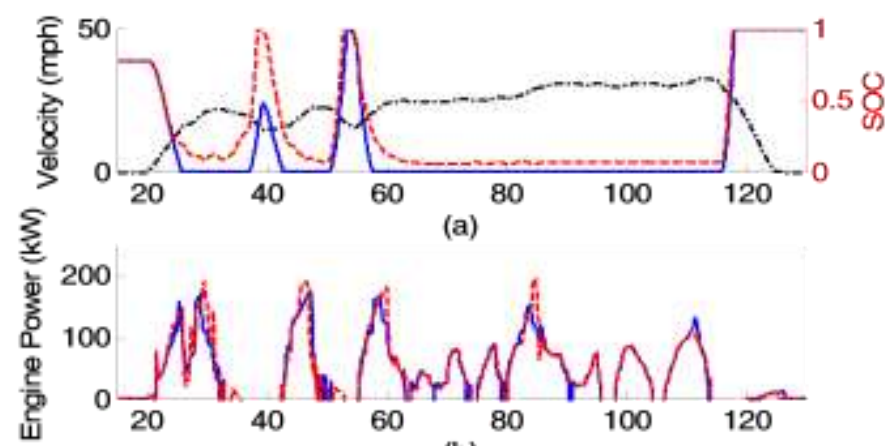

(b)

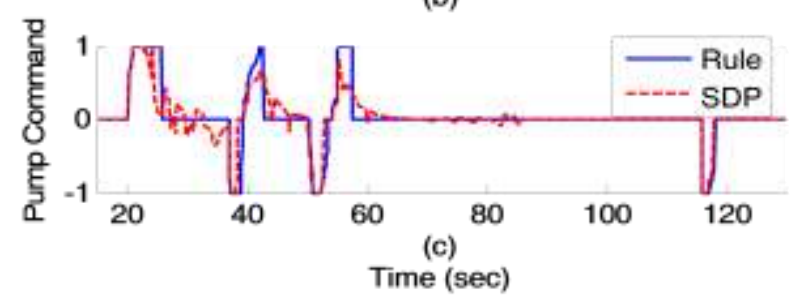

\section{FIGURE 10: SIMULATION RESULTS FOR RULE VS. SDP BASED CONTROLLER DURING SECTION OF FUDS DRIVING CYCLE}

TABLE 4 : PARALLEL HYDRAULIC HYBRID FUEL ECONOMY

\begin{tabular}{cccc}
\hline & & $\begin{array}{c}\text { Rule Based } \\
\text { Controller }\end{array}$ & $\begin{array}{c}\text { SDP based } \\
\text { controller }\end{array}$ \\
\hline \multirow{2}{*}{ Cycle 1 } & MPG & 2.96 & 3.091 \\
& Improvement & $13.05 \%$ & $17.92 \%$ \\
\hline Cycle 2 & MPG & 2.83 & 2.99 \\
& Improvement & $12.07 \%$ & $18.12 \%$ \\
\hline \multirow{2}{*}{ Cycle 3 } & MPG & 2.39 & 2.53 \\
& Improvement & $16.64 \%$ & $23.57 \%$ \\
\hline
\end{tabular}

Table 4 shows the fuel economy predictions of parallel hydraulic hybrid refuse truck over actual driving schedules recorded in a medium size city in Texas, along with percent improvement over baseline conventional vehicle. The table shows the predictions for both controllers, namely rule based and SDP based. It is evident from the fuel economy numbers that both the controllers achieve significant improvement over baseline with SDP providing tangible additional benefits. The additional $5 \%$ gain in fuel economy over baseline rule based 
strategy is achieved without any additional hardware modification. In addition, the controller is directly implementable in practical system as a set of state feedback lookup tables, and hence enables robust operation.

\section{CONCLUSIONS}

A new SDP based power management controller for parallel hydraulic hybrid vehicle is developed. The proposed controller shows the advantage of simultaneous optimization of power split parameters in the parallel hybrid system and gear shift logic. The key contributions of this study are

- Hydraulic hybrid model of refuse truck is developed in SIMULINK for this study. The physics based models of system components and energy storage allow in depth studies with different architecture and power management strategies.

- The stochastic dynamic programming is setup using real world driving cycles for refuse truck. The objective of SDP is to maximize the combined efficiency of the powertrain namely engine, transmission and hydraulic motor. The final strategy is implemented as full state feedback lookup table which makes for a very robust practical controller.

- Rather than addressing only the management of two power sources onboard, the SDP algorithm optimizes the gear shifts too.

The combined optimization of gear shift schedule and power split between engine and hydraulics revealed additional fuel economy potential of $3-5 \%$ over rule based controller derived from earlier work done with dynamic programming.

\section{ACKNOWLEDGEMENTS}

The authors will like to thank Bosch Rexroth for technical and financial support. Technical discussions and data provided by Paul Schwark (Bosch-Rexroth) are also gratefully acknowledged.

\section{REFERENCES}

[1] Wu, B. , Lin, C. C., Filipi, Z. , Peng, H. , and Assanis, D. , 2004, "Optimal power management for a hydraulic hybrid delivery truck," Vehicle System Dynamics, 42(1-2), pp. 23-40.

[2] Filipi, Z. , Louca, L. , Daran, B. , Lin, C.-C. , Yildir, U. , Wu, B. , Kokkolaras, M. , Assanis, D. , Peng, H. , Papalambros, P. , Stein, J., Szkubiel, D. , and Chapp, R. , 2004, "Combined optimisation of design and power management of the hydraulic hybrid propulsion system for the 6 X 6 medium truck," International Journal of Heavy Vehicle Systems, 11(3-4), pp. 372-402.

[3] Kim, Y. and Filipi, Z. , 2007, "Simulation Study of a Series Hydraulic Hybrid Propulsion System for a Light Truck," SAE Transactions, Journal of Commercial Vehicles, 116(2007-01-4151), pp. 147-161.

[4] Lin, C. C., Filipi, Z. , Louca, L. , Peng, H. , Assanis, D. , and Stein, J. , 2004, "Modelling and control of a medium- duty hybrid electric truck," International Journal of Heavy Vehicle Systems, 11(3-4), pp. 349-371.

[5] Pourmovahed, A. , Beachley, N.H. , and Fronczak, F.J. , 1992, "Modeling of a hydraulic energy regeneration system. Part I. Analytical treatment," Journal of Dynamic Systems, Measurement and Control, Transactions of the ASME, 114(1), pp. 155-159.

[6] Alson, J., Barba, D. , Bryson, J., Doorag, M. , Haugen, D. , Kargul, J. , McDonald, J. , Newman, K. , Platte, L. , and Wolcott, M. , 2004, "Progress Report On Clean And Efficient Automotive Technologies Under Development At Epa," :MRN:EPA420-R-04-002, Environmental Protection Agency,.

[7] Pourmovahed, A. , Baum, S.A. , Fronczak, F.J. , and Beachley, N.H. , 1988, "Experimental Evaluation Of Hydraulic Accumulator Efficiency With And Without Elastomeric Foam.," Journal of Propulsion and Power, 4(2), pp. 185-192.

[8] Paganelli, G. , Guerra, T.M. , Delprat, S. , Santin, J. , Delhom, M. , and Combes, E. , 2000, "Simulation and assessment of power control strategies for a parallel hybrid car," Proceedings of the Institution of Mechanical Engineers, Part D (Journal of Automobile Engineering), 214( D7), pp. 705-17.

[9] Farrall, S.D. and Jones, R.P. , 1993, "Energy management in an automotive electric/heat engine hybrid powertrain using fuzzy decision making," Proceedings of the 1993 IEEE International Symposium on Intelligent Control, pp. 463-468.

[10] Baumann, B. M., Washington, G. , Glenn, B. C., and Rizzoni, G. , 2000, "Mechatronic design and control of hybrid electric vehicles," IEEE/ASME Transactions on Mechatronics, 5(1), pp. 58-72.

[11] Lin, C. C., Filipi, Z. , Wang, Y. , Louca, L. , Peng, H. , Assanis, D. , and Stein, J. , 2001, "Integrated, FeedForward Hybrid Electric Vehicle Simulation in SIMULINK and its Use for Power Management Studies," SAE Technical Paper 2001-01-1334.

[12] Sciarretta, A. and Guzzella, L. , 2007, "Control of hybrid electric vehicles," IEEE Control Systems Magazine, 27(2), pp. 60-70.

[13] Lin, C. C., Peng, H. , and Grizzle, J.W. , 2004, "A stochastic control strategy for hybrid electric vehicles," Proc. of American Control Conference, 5, pp. 4710-4715.

[14] Liu, J. , Hagena, J. , Peng, H. , and Filipi, Z.S. , 2008, "Engine-in-the-loop study of the stochastic dynamic programming optimal control design for a hybrid electric HMMWV," International Journal of Heavy Vehicle Systems, 15( 2-4), pp. 309-26.

[15] Johri, R. and Filipi, Z. , 2010, "Low-Cost Pathway to Ultra Efficient City Car: Series Hydraulic Hybrid System with Optimized Supervisory Control," SAE International Journal of Engines, 2(2009-24-0065), pp. 505-520. 
